\title{
The Computational Model of the Peak Regulation Capacity of Cogeneration Units and Its Application
}

\author{
Junshan Guo ${ }^{1, a}$,Junqi Ding ${ }^{1}$, Lingkai Zhu ${ }^{1}$, Yongqiang Che ${ }^{1}$, Wei Zheng ${ }^{1}$ Yihe $\mathrm{Ma}^{1}$ and Yang Wang ${ }^{2}$ \\ ${ }^{1}$ State Grid ShanDong Electric Power Research Institute, Jinan 250003,China; \\ ${ }^{2}$ ShanDong Hengli New energy engineering CO.Ltd , Jinan 250101,China
}

\begin{abstract}
Studying the peak regulation capacity of cogeneration units is of positive significance to improve the power grid dispatching capacity and promote the new energy source. In order to scientifically calculate the peak shaving capacity of a cogeneration unit, the variable condition calculation model is built up based on the theory of equivalent heat drop, and the load constraint model is also established according to the actual situation, on this basis the complete computational model of the peak regulation capacity of cogeneration units is obtained. Based on a 350MW cogeneration unit in Shandong province, the peak regulation capacity calculation is carried out, and the factors affecting the peak regulation capacity of the unit are analyzed. Compared with the experimental results, the calculation model of the peak regulation capacity in this paper shows a high precision, and can be used to predict the peak regulation capacity of the cogeneration units in different working conditions.
\end{abstract}

\section{Introduction}

With the rapid development of the socio-economic, the peak-to-valley difference in the power load is increasing, and the difficulty in the peak shaving of the power grid is increasing. In recent years, wind power generation, hydropower generation, solar power generation, nuclear power generation, and various new energy generation ratios have continuously increased. These new energy sources are basically unable to participate in the peaking of the power grid and the power generation has great randomness, further exacerbating the pressure of the peaking of the power grid $^{[1-2]}$. It has been difficult to meet the needs of grid peaking relying on pure condensing cogeneration units, so it is necessary to find new peaking power supplies. The cogeneration units occupies a considerable proportion in China, especially in the northern regions. Researching the peak shaving capacity of cogeneration units is of positive significance for upgrading the dispatch capability of the power grid and promoting the consumption of new energy sources.

In general, there are three methods to determine the peak shaving capacity of a cogeneration unit: test method, condition diagram method, and thermal calculation method. The test method can accurately reflect the actual peak shaving capacity of the cogeneration unit ${ }^{[3]}$, but it is difficult to implement. Condition diagram method is only applicable to specific units or specific conditions ${ }^{[4]}$. The thermal calculation method is actually to calculate the varying condition of the cogeneration unit under certain constraint conditions. Among the three methods, the thermal calculation method is universal and can be modified when the operating condition of the unit changes, and has been widely studied by scholars. Zhu $\mathrm{Yu}{ }^{[5]}$ took the subcritical $330 \mathrm{MW}$ cogeneration unit as an example, obtained the operating characteristics of the unit using the equivalent thermal drop method, and analyzed the peak operation characteristics of the cogeneration unit. However, the research focuses on the study of economics of peak shaving, and does not introduce the constraint on the peak output of thermoelectric units. Wang Wei ${ }^{[6]}$ obtain the output range of the cogeneration unit under different working conditions adopting the method of simplified variable condition calculation, and introduced the boundary conditions of the peak load output. However, it does not consider the limitations of environmental protection equipment when the unit is operating at peak load, so the results obtained have certain limitations.

Based on the above analysis, the calculation of the peaking capacity of the cogeneration unit needs to be explored in terms of the accuracy of the calculation model and completeness of constraints. Therefore, the variable condition calculation model of the cogeneration unit based on the equivalent thermal drop theory ${ }^{[7]}$ is reestablished in this paper, and the constraints of the peak regulation according to the actual problems in operation is put forward, finally, the accuracy of the model is tested combined with the peaking unit verification test in Shandong province. On this basis, the factors affecting the peak shaving capacity of cogeneration unit are analysed.

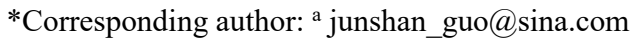




\section{The calculation model of peaking capacity of cogeneration unit}

\subsection{Variable condition calculation model}

The variable condition calculation for a cogeneration unit is a complex calculation which combines variable condition calculation of the steam turbine and the calculation of the thermal system.

(1) Baseline condition calculation

Baseline condition calculation is the basis for variable condition calculations. The rated steam extraction conditions of the unit is selected as the baseline conditions in this paper. The main goal of the calculation is to determine the parameters such as the flow rate of the main steam $D_{00}$, the flow rate of the extraction steam $\mathrm{D}_{\mathrm{r} 0}$, and the thermal economic indicators.

(2) Calculation of the extraction pressure

The extraction pressure under variable conditions is determined according to the Frugell formula, as shown in equation (1):

$$
\frac{D_{1}}{D_{10}}=\sqrt{\frac{\left(P_{1}^{2}-P_{2}^{2}\right)}{\left(P_{10}^{2}-P_{20}^{2}\right)}} \sqrt{\frac{T_{10}}{T_{1}}}
$$

Where, $D$-flow rate of the steam through the stage group; $P_{1}$-Steam pressure before the stage group; $P_{2-}$ Steam pressure after the stage group; $T_{1}$-Steam temperature before the stage group; Subscript 0 represents the parameters under the baseline condition.

Combined with the characteristics of the cogeneration unit, it is generally divided into three sections: the adjustment stage to the industrial extraction point, the industrial extraction point to the heating extraction point, and the heating extraction point to the condenser. The extraction pressure of each segment can be calculated as shown in equation (2)

$$
P_{r}=\sqrt{P_{2}^{2}+\left(\frac{D_{1}}{D_{10}}\right)^{2}\left(P_{r 0}^{2}-P_{20}^{2}\right)}
$$

Where, subscript $\mathrm{r}$ represents the parameters of the extraction.

(3) Calculation of the exhaust pressure

The exhaust pressure is calculated by the thermodynamic calculation of the condenser. Regardless of the heat exchange between the condenser and the external environment, the temperature of the saturated steam can be deduced as follows:

$$
t_{s}=t_{w 1}+\left(1+\frac{1}{e^{\frac{A_{c} K\left(t_{w 1}\right)}{4187 D_{w}}}-1}\right)\left[\frac{1000 D_{c}\left(h_{c}-h_{c}^{\prime}\right)}{4187 D_{w}}\right]
$$

The corresponding pressure of the saturated steam can be calculated as follows:

$$
p_{s}=p\left(t_{s}\right)
$$

Where, $p\left(t_{s}\right)$ is a function of the saturation vapor pressure with respect to temperature

(4) Calculation of the expansion line

When the operating condition changes, the efficiency of the regulating stage and the final stage changes greatly, while the efficiency of the intermediate stage group almost remained unchangeable. Therefore, the expansion line of the intermediate unit can be obtained by translating the expansion line under baseline condition. The expansion line of the regulating stage and the final stage can be deduced according to the variable operating condition curve provided by the turbine manufacturer. After the expansion process line of the variable condition is determined, the extraction enthalpy under new conditions can be determined based on the new extraction pressure in the enthalpy-entropy diagram.

(5) Calculation of soda parameters of thermal system

In the model constructed in this paper, it is considered that the regenerative heaters work according to the design performance, ie, the heater end difference and extraction pressure loss keep the design value unchanged; the outlet water temperature equals the saturation temperature corresponding to the extraction pressure minus the upper end of the heater. Poor; hydrophobic temperature is equal to the heater inlet water temperature plus the hydrophobic terminal difference. The heat loss of the water pump will be ignored, and the enthalpy increase can be calculated as follows:

$$
\tau_{b}=\int_{1}^{2} v d p
$$

After the above parameters are determined, the equivalent thermal drop of the new steam and the main steam can be calculated according to the equivalent heat drop theory, as shown in the following formulas.

$$
\begin{gathered}
H=h_{0}+\sigma-h_{n}-\sum_{r=1}^{z} \tau_{r} \eta_{r}-\sum \Pi \\
\left(H+\tau_{b}\right) D=\frac{N_{d}}{\eta_{j x} \eta_{d}}
\end{gathered}
$$

Where, $H$ - main steam equivalent heat drop, the calculation method of which is described in detail in the literature [7]; $D$ - Main steam flow; $\eta_{j x}, \eta_{d}$-mechanical efficiency and motor efficiency.

\subsection{Constraints model}

According to the current situation of the actual operation of the power grid, the main problem of the peaking of cogeneration units is to study their low-load output capabilities. This article mainly analyses the low load limit conditions of the cogeneration unit.

(1) Limit of minimum intake steam volume of lowpressure cylinder

In order to prevent the low-pressure cylinder from entering the air blowing state, the cogeneration unit must ensure that there is sufficient cooling flow into the lowpressure cylinder during the load-reducing process. The minimum cooling flow rate of the low pressure cylinder is related to the design and operation status of the unit. The cooling flow rates required for the different exhaust gas back pressures and different low pressure cylinder blades are different, and will be given by the manufacturer in the heating condition diagram.

$$
D_{n}>D_{n}^{\min }=f\left(D_{0}, D_{c n}, D_{s g}\right)
$$

(2) Boiler stability conditions 
When the cogeneration unit participates in the peak shaving of the power grid, it must ensure that the boiler can be stably burned, that is, the fuel amount must meet the requirement for stable combustion. In the case where the ratio of water to coal is known, the main steam flow must be greater than the corresponding limit flow for steady combustion of the boiler.

$$
D_{0}>D_{0}^{w r}
$$

(3) Flue gas temperature limit of the SCR equipment

At present, thermal power generators generally use $\mathrm{SCR}$ equipment to remove nitrogen oxides $\left(\mathrm{NO}_{\mathrm{x}}\right)$ in the flue gas, and the $\mathrm{NO}_{\mathrm{x}}$ emission from the power station is strictly limited. Therefore, the SCR equipment needs to maintain efficient operation at all times. When the electrical load of the unit is reduced, the pressure of the reheated extraction is reduced, the temperature of the feedwater is decreased, and the amount of fuel decreases with the decrease of the load. The temperature of the flue gas at the outlet of the economizer decreases, resulting in a decrease in the efficiency of SCR denitration, and in severe cases, the denitration system will be brought out of operation, $\mathrm{NO}_{\mathrm{x}}$ emissions exceeded. Due to this limitation, it is necessary to ensure that the flue gas temperature at the economizer outlet is greater than the lower limit temperature at which the SCR device is put into operation. Therefore, the calculation model of the peaking capacity of the cogeneration unit also requires the thermal calculation of the boiler to obtain the temperature of the flue gas at the exit of the economizer to ensure that the temperature can meet the requirements for the commissioning of the SCR equipment.

Finally, the calculation model is obtained by integrating the variable condition calculation model and the constraint condition model. In the specific calculation, under the given heat supply requirements, by continuously assuming the main steam flow, the computer group output and various performance parameters, when the boundary conditions defined by the constraint model are reached, the output of the unit reaches the minimum value, which reflects peak shaving capacity of the cogeneration unit.

\section{Calculation Example}

In order to verify the accuracy of the model, this paper takes a C350-24.2/0.4/566/566 unit in Shandong as the research object, and calculates its peak shaving capacity. The unit was tested in peak capacity in January 2017. The test results showed that the minimum electrical load of the unit is $141 \mathrm{MW}$ under the condition of meeting the heating demand of the whole plant. Continuing to reduce the load will cause the SCR equipment to quit operation. This article compares the experimental results with the model calculation results, as shown in Table 1 .

Table 1. Comparison between model calculation and test results.

\begin{tabular}{ccccc}
\hline Name & Unit & $\begin{array}{c}\text { Test } \\
\text { Data }\end{array}$ & $\begin{array}{c}\text { calculation } \\
\text { results }\end{array}$ & $\begin{array}{c}\text { Relative } \\
\text { error(\%) }\end{array}$ \\
\hline $\begin{array}{c}\text { Reheat pressure } \\
\text { Exhaust pressure }\end{array}$ & $\mathrm{MPa}$ & 2.05 & 2.11 & 2.93 \\
$\mathrm{kPa}$ & 3.27 & 3.09 & 3.73
\end{tabular}

$\begin{array}{ccccc}\begin{array}{c}\text { Deaerator outlet } \\ \text { temperature }\end{array} & { }^{\circ} \mathrm{C} & 145.9 & 147.1 & 0.82 \\ \# 3 \text { heater outlet } & { }^{\circ} \mathrm{C} & 186.7 & 187.2 & 0.27 \\ \begin{array}{c}\text { temperature } \\ \text { \#2 heater outlet }\end{array} & { }^{\circ} \mathrm{C} & 221 & 221.6 & 0.27 \\ \begin{array}{c}\text { temperature } \\ \# 1 \text { heater outlet } \\ \text { temperature }\end{array} & { }^{\circ} \mathrm{C} & 247.5 & 245.9 & 0.65 \\ \begin{array}{c}\text { Main steam flow } \\ \# 1 \text { team extraction } \\ \text { pressure }\end{array} & \mathrm{t} / \mathrm{h} & 594.1 & 592.2 & 0.32 \\ \begin{array}{c}\# 2 \text { team extraction } \\ \text { pressure }\end{array} & \mathrm{MPa} & 3.52 & 3.52 & 0.07 \\ \begin{array}{c}\text { Active power } \\ \text { Economizer outlet }\end{array} & \mathrm{MW} & 170 & 168.4 & 0.94 \\ \text { flue gas temperature } & { }^{\circ} \mathrm{C} & 313.2 & 315.0 & 0.60\end{array}$

From Table 1, it can be seen that the output of the model computer group is in good agreement with the experimental measurement results, and the calculation error of the main parameters of the unit is within $4 \%$; in addition, as shown in Figure 1, the main factor that restricts the unit to continue to reduce the output is The SCR exited the operation, and the inlet flow of the low pressure cylinder and the steady combustion of the boiler did not affect the peaking operation of the unit. This result is consistent with the test results. The above results show that the calculation of the peak shaving capacity of the cogeneration unit established in this paper can accurately change the operating conditions of the computer group and can be used to predict the peak shaving capacity of the cogeneration unit under different working conditions.

In order to further study the peak shaving capacity of the cogeneration unit, this paper analyses the variation of the unit's minimum output with changes in the heating flow. The results are shown in Figures 2 and 3.

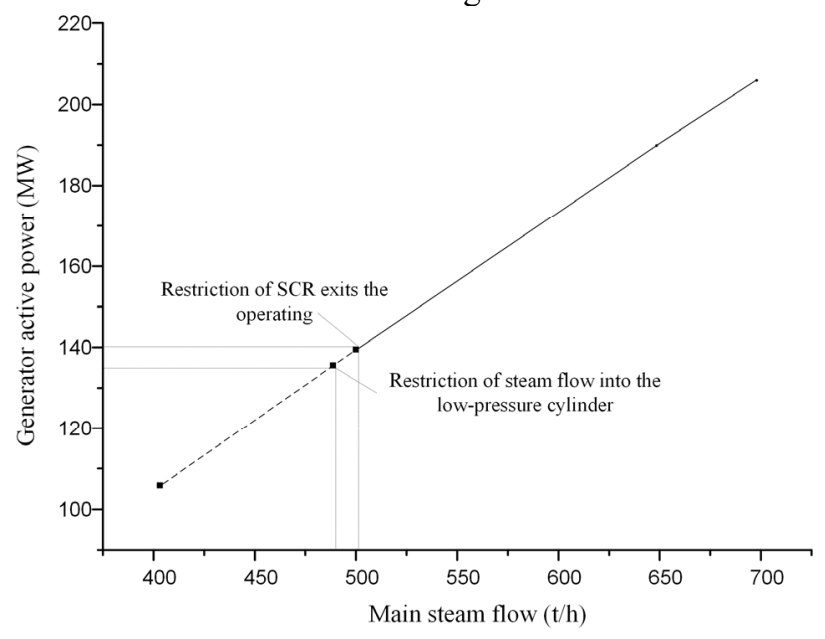

Fig1. The minimum output limit conditions 


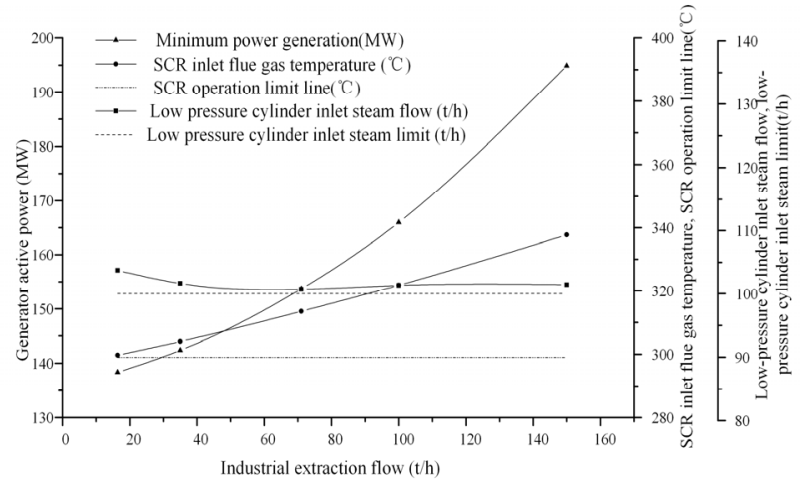

Fig2. The relationship between peaking capacity of the unit and industrial extraction

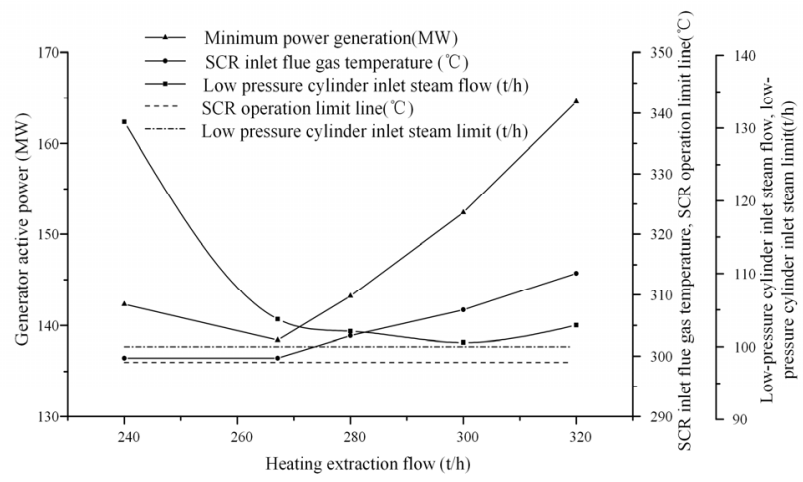

Fig3. The relationship between peaking capacity of the unit and industrial extraction

\section{Conclusion}

Based on the theory of equivalent thermal drop, a calculation model for variable condition of steam turbine for cogeneration unit is established. According to the actual operation conditions, several conditions for limiting the minimum output of cogeneration unit are analysed and a mathematical model is established. On this basis, the peak capacity calculation model of the cogeneration unit is established. Taking a C35024.2/0.4/566/566 unit in Shandong as the research object, its peak-shaving capability was calculated, and the influencing factors of the unit's peak-shaving ability were analysed. The following conclusions can be drawn:

a) Comparing with the test results, the calculation model built in this paper is of high accuracy, and can accurately calculate the limit conditions. So the model can be used to predict the peak shaving capacity of the cogeneration unit under different working conditions.

b) Under the premise of satisfying the heating demand, the cogeneration unit generally reduces the output of the unit by reducing the main steam flow. As the main steam flow decreases, the SCR inlet flue gas temperature decreases, and the operation of the SCR equipment is major factor affect the cogeneration unit. The factor of the lowest output is that the inlet flow rate of the low-pressure cylinder of the steam turbine and the stable combustion condition of the boiler will not limit the peak operation of the cogeneration unit during the actual operation. c) When the heating flow continues to increase on the basis of the rated flow, in order to ensure the inlet volume of the low pressure cylinder, the main steam flow of the unit increases, the minimum output of the thermal power unit increases, the temperature of the SCR inlet flue gas increases, and the operation of the SCR device is no longer the determining factor. The inlet flow rate of the low pressure cylinder becomes the main factor limiting the output of the cogeneration unit.

\section{References}

1. L YAO, J GUO, X WANG. Turbine Technology, $51,61,2009$.

2. X LI. Northeast Electric Power University,2009.

3. H WANG, Y FENG, L FENG. Thermal Power Generation, 43,106,2014

4. L ZHANG, $\mathrm{X}$ ZHANG, $\mathrm{S}$ YUAN. Turbine Technology, 58 ,391,2016.

5. Y ZHU, Q LI, Y FENG. Thermal Power Generation, 6, 7, 2014.

6. Y WANG, Y XUE, N DENG. Electric Power, 46, 59,2013

7. W LIN. Thermal power plant thermal energy conservation theory(Xi'an Jiaotong University Press, 1994) 